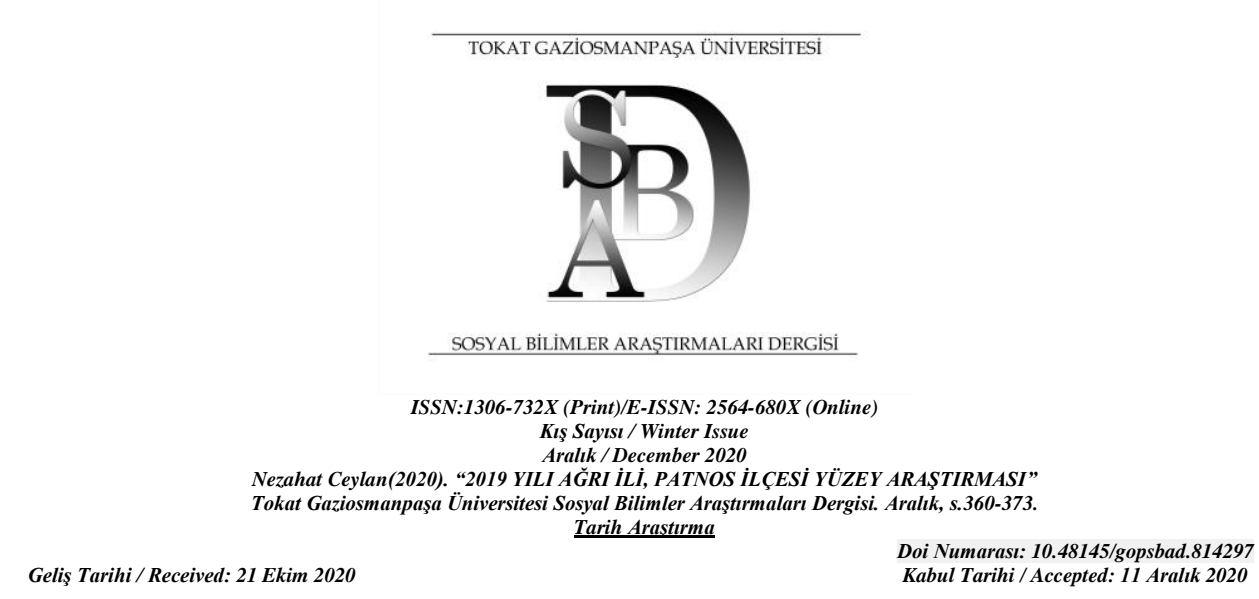

\title{
2019 YILI AĞRI İLİ, PATNOS İLÇESİ YÜZEY ARAŞTIRMASI
}

\author{
Nezahat CEYLAN ${ }^{1 *+}$ \\ ${ }^{1}$ Doç. Dr. Atatürk Üniversitesi, Edebiyat Fakültesi, Tarih Bölümü \\ *bceylanerzurum@hotmail.com \\ ${ }^{+}$ORCID: 0000-0002-9889-7279
}

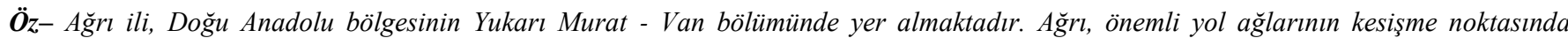
bulunmaktadır. Bölgenin en önemli su kaynağını, Fırat Nehri'nin önemli bir kolu olan Murat Nehri ve kolları oluşturmaktadır. Geç Kalkolitik Çăg'dan itibaren yerleşim gören A ğrı'da, İlk Tunç Çağı'nda Karaz Kültürü etkili olmuştur. Bölgede, geçmişten günümüze kadar gerçekleştirilen yüzey araştırmaları ve bilimsel kazılar neticesinde, bölgenin Eskiçă̆ Tarihi'ni aydınlatan önemli veriler elde edilmiştir. Bu çalışmada, 2019 yılında Patnos ilçesinde gerçekleştirilen yüzey araştırması sonucunda incelenen merkezler, gerek mimari yapıları ve gerekse keramik verileri ışı̆̆ında ele alınmıştır.

Anahtar Kelimeler-A Ăgrı, Patnos, Karaz Kültürü, Urartu Krallı̆̆ı.

\section{AGRI PROVINCE, PATNOS DISTRICT SURFACE RESEARCH}

Abstract - A $\breve{g r l}$ province is located in the Yukarl Murat - Van section of the Eastern Anatolia region. A $\breve{g r l}$ is at the intersection of important road networks. The most important water source of the region is the Murat River and its branches, which are important branches of the Euphrates River. Karaz Culture was effective in the First Bronze Age in A $\breve{g r l}$, which was settled since the Late Chalcolithic Age. As a result of surface surveys and scientific excavations carried out in the region from the past to the present day, important data were obtained that illuminated the Ancient History of the region. In this study, the centers examined as a result of the excavation carried out in Patnos district in 2019 were discussed in the light of both architectural structures and stoneware data.

Keywords - Ağrl, Patnos, Karaz Culture, Urartian Kingdom. 


\section{GíRiş}

Kültür ve Turizm Bakanlığı'nın 94949537-161.01-720199 sayı ve 04.09.2019 tarihli izinleriyle başkanlığımdaki ekiple yürütülen 2019 yılı Ağrı ili, Patnos ilçesi yüzey araştırması, 09-19 Eylül 2019 tarihleri arasında gerçekleştirilmiştir ${ }^{1}$.

Arazi çalışmalarına Prof. Dr. Alpaslan CEYLAN ve Dr. Öğr. Üyesi Gökhan KALMIŞ katılmıştır. Bakanlık temsilciliği görevini ise Tahir KAHRAMAN üstlenmiştir ${ }^{2}$. Çalışma sahasının haritalandırılması ve teknik destekleri; Prof. Dr. Ümit KILIÇ, Dr. Öğr. Üyesi Oğuz ŞİMŞEK, Dr. Öğr. Üyesi Hacer KUMANDAŞ YANMAZ ve Arş. Gör. Burak BINGÖL tarafından gerçekleştirilmiştir. Yüzey araştırması laboratuvar çalışmaları ise, Murat ÇíFTÇI, Uğur KARCIOĞLU, Emine ÇALBAY, Betül NIŞANCI, Mehmet Akif ARSLAN, Halil İbrahim YILMAZ, Nazik LAÇiNOK, Tuba ÖKSÜZ ve Ayşe KARAMAN tarafindan yürütülmüştür.

Çalışma sahamızın da sınırları içerisinde yer aldığı Ağrı ili, Doğu Anadolu bölgesinin Yukarı Murat - Van bölümünde bulunmaktadır. İlin doğusunda İran, kuzeyinde Kars ve Iğdır, batısında Erzurum ve Muş, güneyinde ise Bitlis, Van ve İran bulunmaktadır. İlin yüzölçümü $11.376 \mathrm{~km}^{2}$ olup ülkemiz topraklarının \% 1,4'lük kısmını meydana getirmektedir (Yazgan-Kadanal1, 2012: 7; Kocaman-Kaya, 2014: 17).

İl topraklarının \% 46'sını dağlar, \% 29'unu ovalar, \% 18'ini platolar ve \% 7'sini ise yaylalar oluşturmaktadır. Bölge halkının ana geçim kaynağı tarım ve hayvancılıktır. Ağrı ve çevresinde, tarım açısından oldukça verimli ovalar yer almaktadır. Bu ovalar; Eleşkirt Ovası, Doğubayazıt Ovası, Tutak Ovası ve Patnos Ovası'dır. İlde, ülkemizin en büyük dağı olan Ağrı Dağı (5137 m) ve Küçük Ağrı Dağı (3896 m) başta olmak üzere Tendürek (3343 m), Süphan (4058 m), Hama Dağı, Aşağı Dağ (3279 m), Karadağ (3250 m) ve Aladağ (3250 m) gibi önemli dağlar bulunmaktadır (YazganKadanal1, 2012: 7).

Ağrı ili ve Patnos ilçesi, önemli yol ağlarının kavşak noktasında yer almaktadır. Geçmişten günümüze kadar yoğun bir şekilde kullanılan ticaret yollarından biri olan ve Erzurum üzerinden Tebriz'e ulaşan yol ağı oldukça stratejik bir konuma sahiptir. $\mathrm{Bu}$ yol, batı yönünden Trabzon Gümüşhane - Bayburt - Erzurum - Hasankale - Tahir Geçidi Eleşkirt - Ağrı - Taşlıçay - Doğubayazıt üzerinden gelerek Kuzeybatı İran'a ulaşmaktadır. Bu yolun Ağrı'dan ayrılan kolu Hamur-Tutak'tan geçerek Patnos'a ulaşır. Yol ağı, Patnos'tan devam ederek Erciş'ten Van'a varmaktadır. Erzurum - Van arasındaki yol ağının en önemli durak noktalarından birini ise Patnos oluşturmaktadır (Yıldız, 1996:

${ }^{1}$ Bu projeye, Türk Tarih Kurumu tarafından maddi destek sağlanmıştır. Yardımlarından dolayı Türk Tarih Kurumu'na teşekkür ederiz.

${ }^{2}$ Yüzey araștırmaları sırasında gösterdikleri anlayıs ve sağladıkları katkılardan dolayı ekip üyelerine, bakanlık temsilcimiz Tahir KAHRAMAN'a ve bu çalışmanın gerçekleşmesinde büyük katkıları olan Atatürk Üniversitesi Rektörü Prof. Dr. Ömer ÇOMAKLI'ya teşekkür ederiz. Ayrıca Patnos'ta bizden yardımlarını esirgemeyen, her türlü desteği sağlayan Patnos İlçe Kaymakamı Enver ÖZDERİN, Milli Eğitim Müdürü Yakup TAȘDEMİR, Öğretmen Evi Müdürü Mansur VURAL ve öğretmen Ender KARA'ya sonsuz teşekkür etmeyi bir borç bilmekteyiz.
60; Ceylan, 2008: 43 vd.; Kocaman-Kaya, 2014: 85; Ceylan, 2015: 77 vd.; Ceylan, N. 2016: 656 vd.; Ceylan-Günaşdı, 2018: $54 \mathrm{vd}$.).

Patnos ilçesi, $1.420 \mathrm{~km}^{2}$ 'lik bir alanı kaplamakta, il topraklarının yaklaşık \% 7,9'unu oluşturmaktadır. İlçenin kuzeyinde Ağrı ilinin Tutak ve Hamur ilçeleri, batısında Muş'un Malazgirt ilçesi, güney ve güneydoğusunda Bitlis'in Adilcevaz ilçesi ve doğusunda ise Van'ın Erciş ilçesi yer almaktadır. Patnos, geniş bir alana yayılmış olan (yaklaşık $230 \mathrm{~km}^{2}$ ) Patnos Ovası üzerinde bulunmaktadır. Ovanın tarım ve hayvancılık potansiyeli oldukça yüksektir. Yükseltisi 1620-1670 m arasında değişen ova, kuzeyde Aladağlar ve güneyde Süphan Dağı arasında yer almaktadır (Yıldız, 1996: 1 vdd.).

Patnos ve çevresindeki ilk yerleşmelerin, Geç Kalkolitik Çağ'a kadar uzandığını ifade etmek mümkündür. Bölgede, MÖ. IV. binyılın ikinci yarısından itibaren, Doğu Anadolu Bölgesi merkez olmak üzere Transkafkaslar, Kuzeybatı İran, Amik Ovası, Kuzey Suriye ve Filistin'e kadar olan geniş bir coğrafyaya yayılan Karaz Kültürü etkili olmuştur. Kültür, mimari özellikleri ve kendine has keramiği ile ön plana çıkmaktadır. $\mathrm{Bu}$ dönemde bölgede yoğun bir yerleşimin olduğu, geçmişten günümüze kadar gerçekleştirilen yüzey araştırmaları ve bilimsel kazı çalışmaları sayesinde bilinmektedir ${ }^{3}$.

Hurri-Mitanni Devleti'nin tarih sahnesinden çekilmesi neticesinde, Doğu Anadolu bölgesinde Hurri kökenli boylar ve onlarla akraba olan topluluklar beyler etrafinda toplanmışlardır. Doğu Anadolu'nun yüksek yaylalarında yaşayan bu topluluklar, MÖ. XIII-IX. yüzyıllar arasında hüküm süren "Uruatri-Nairi" konfederasyonunu meydana getirmişlerdir. $\mathrm{Bu}$ dönem, bilim adamları tarafından "Urartu'nun Proto Tarihi" veya "Urartu'nun Arkaik Çağı" gibi birden fazla isimle anılmaktadır (Melikişvili, 1960: 13; Van Loon, 1966: 6; Salvini, 1967: 32; Tarhan, 1978: 1 vdd; Erzen, 1992: 24 vdd.; Ceylan, 2015: 486; Günaşd1, 2016: 113 vd.; Özgül, 2016: 137 vd;; Ceylan-Günaşd1, 2017: 319; Üngör, 2018b: 207; Ceylan-Kalmış, 2019: 622).

Uruatri-Nairi konfederasyonları dönemi sonunda beylikler, güçlü düşmanları Asur'a karşı birliktelik sağlayarak Urartu Devleti adı altında birleşmişlerdir (Tarhan, 1978: 72 vd.; Tarhan, 1982: 69 vd.; Baştürk, 2013: 69 vd.; Ceylan-Özgül, 2016: 129; Kalmış, 2019: 2035; Karageçi-Günaşd1, 2019: 653). Doğu Anadolu bölgesinin Eskiçağ Tarihi'nde oldukça önemli bir yere sahip olan Urartular'a ait Patnos ve çevresinde çok sayıda yazıt, kale ve yerleşim yeri tespit edilmiştir. İlçede, Aznavurtepe Kalesi ve Giriktepe Höyüğü'nde bilimsel kazı çalışmaları gerçekleştirilmiştir. Bu

\footnotetext{
${ }^{3}$ Karaz Kültürü hakkında detaylı bilgi için bkz. Maisler-Stekelis vd. 1952: 165-173 Piotrovskii, 1962: 7; Arsebük, 1974; Arsebük, 1986: 67-72; Pehlivan, 1990: 168 vd.; Özgül, 2011: 98 vd.; Karageçi, 2014: 81 vd.; Ceylan, 2015: 479; Sagona-Zimansky, 2015: 167 vd.; Günaşd1, 2016: 117; Özgül, 2016: 142; Üngör, 2018a: 100; Ceylan, N. 2019: 637; Ceylan-Kalmıs, 2019: 621 vd.; Ceylan-Özgül-Kalmıs, 2019: 31; Üngör, 2019: 757; Kalmıș, 2020a: 85 vd.; Kalmıș, 2020b: 156; Morkoç, 2020a: 100 vd.; Morkoç, 2020b: 65 vd.; Morkoç, 2020c: 245 vd.
} 
kazılar neticesinde Urartu mimari tarzında inşa edilmiş yapılar, sur duvar kalıntıları tespit edilmiştir. Ayrıca Giriktepe Höyüğ̈̈'nde ele geçirilen zengin Urartu saray malzemeleri, bu merkezin Urartu Devleti açısından önemini göstermektedir. Bölgedeki Urartu mirasının zenginliğinden hareketle, bu dönemde bölgenin Urartu Devleti açısından büyük bir öneme sahip olduğunu ifade etmek mümkündür ${ }^{4}$.

Urartu Devleti'nin, kuruluşundan kısa süre sonra Patnos'ta inşa faaliyetlerine önem verdiği, bölgede tespit edilen çivi yazılı Urartuca kitabelerden anlaşılmaktadır. Bölgede ilk inşaat faaliyetlerine, kral İšpuini (MÖ. 825-810) döneminde başlanıldığı düşünülmektedir. Patnos'ta bulunan Ziyarettepe'de ele geçirilen bir kitabede "Tanrı Haldi'nin kudretiyle, Sarduri oğlu İšpuini bu ... yaptırdl. (Burada) bunun gibi kusursuz başka hiçbir şey dikilmemişti. Sarduri oğlu İspuini bu ... yaptırdl" ifadeleri yer almaktadır (Hyvernat, 1892: 560-565, no. 26; Sayce, 1893: no. 69; Sandalgian, 1900: no. 56; Belck-Lehmann, 1900a-b: no. 13; Hulin, 1958: 242, no. 32; Güterbock, 1963: 268-269, no. 4; Lehmann-Haupt, 1928-35: no. 7, 9; Melikişvili, 1960: no. 14,16; König, 1955: 296-297, no. 3,4; König, 1955-57: no. 5b; Payne, 2006: 22-23). Urartu Devleti'nin bölgedeki inşa faaliyetleri, daha sonraki dönemlerde de yoğun bir şekilde devam etmiştir (Balkan, 1964: 235 vd.).

Bölgedeki araştırmalarımızın ilk dönemi olan 2019 yılı çalışmaları oldukça verimli geçmiş, bölgenin Eskiçağ Tarihi'ne ve arkeolojisine 1şı tutması açısından önemli sonuçlar ortaya koyacağını düşündüğümüz 19 sit ve 1 anıt merkezinde incelemelerde bulunulmuştur.

\section{Aznavurtepe Kalesi ${ }^{5}$}

Ağrı ili, Patnos ilçesinde yer alan kale 1848 m yüksekliktedir. Kale, günümüzde askeri saha içerisinde bulunmaktadır (Foto. 1). Kalenin zeminden yüksekliği 208 m'dir. Kalenin giriş kapısı dalgalı olup, ilk açıklık $4.40 \mathrm{~m}$ iken ikinci dalga ise 3.60 m'dir. Kalenin en üst zirvesindeki stadel ise kare planda olup $12.10 \mathrm{~m}^{2}$ dir. Stadelin girişi ise güneydoğuda yer almaktadir.

Kalede, 1957 yilında C. A. Burney ve G. R. J. Lawson tarafından yüzey araştırmaları gerçekleştirilmiştir ${ }^{6}$. 19611963 yılları arasında K. Balkan tarafindan bilimsel kazı çalışmaları yürütülen kalenin sathında tespit edilmiş olan kitabede, kral Argişti I'in (MÖ. 786-764) burada bir zahire deposu inşa ettirdiğinden bahsedilmektedir. Taş bir blok üzerinde bulunan kitabede şu ifadeler yer almaktadır: "Tanr Haldi'nin kudretiyle Minua oğlu Argišti bu tahıl deposunu

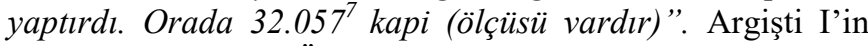
oğlu Sarduri III (MÖ. 645-635) döneminde de kalede inşa faaliyetleri devam etmiştir. Yine bu faaliyetler hakkındaki bilgileri de, kalede tespit edilen yazıtlardan edinmekteyiz

\footnotetext{
${ }^{4}$ Urartu Devleti hakkında geniş bilgi için bkz. Tarhan, 1978; Pehlivan, 1991; Ceylan, 1994; Salvini, 2006; Ceylan, 2015: 486 vd.

${ }^{5} 4550016 \mathrm{D}-3915006 \mathrm{~K}$

${ }^{6}$ Detaylı bilgi için bkz. Burney-Lawson, 1960: 192 vd.

Bu sayıyı Balkan 31.045, Melikișvili 32.045, Payne ise 32.057 olarak okumuștur. Balkan, 1960: no: 4; Melikişvili, 1971: no. 402; Payne, 2006: 192.
}

(Balkan, 1964: 235 vd.; Kozbe-Ceylan vd. 2008: Anzavurtepe; Payne, 2006: 242, 260).

Kalede tespit edilen Haldi Tapınağı'nın büyük bir kısmı 1961-1963 yılları arasında açılmıştır. Bu alanda bulunan kitabeye göre ise binanın, kral Menua tarafından inşa ettirildiği anlaşılmaktadır. Kuzeybat1-güneydoğu yönünde inşa edilen binanın giriş kısmı güneydoğuya bakmaktadır. Tapınak odasının içi, önü, yanları ve arkası oda tabanından 3$8 \mathrm{~m}$ arasında yükselen ince dolgu toprağı ile doldurulmuştur. Binanın günümüze kadar, iyi bir şekilde korunarak gelmesinde bu dolgunun etkili olduğunu ifade etmek mümkündür (Balkan, 1964: 237 vd.).

Aznavurtepe'nin doğu, güney ve batı yamaçlarında, tepeden 60-70 m aşağıda yapı kalıntıları tespit edilmiştir. Kalenin batı yamacında, $5 \mathrm{~m}$ kalınlığa sahip Urartu taş işçiliği özellikleri taşıyan sur duvar kalıntısı tespit edilmiştir. Yer yer 4 m'den daha yüksek olan duvarın 60 m'den fazla kısmı açılmıştır. Surun doğuya bakan kısmında, doğal kayaya dayanmakta olan büyük bir kapı bulunmaktadır (Balkan, 1964: 239).

Kalede, çok sayıda Urartu çivi yazılı kitabe ele geçirilmiştir. Bu durum, kalenin Urartu döneminde büyük bir öneme sahip olduğunu göstermektedir ${ }^{8}$. Kaledeki tapınak kapısının sağ tarafında, duvarın dış cephesindeki iki bazalt üzerinde tespit edilen yazıtta şu ifadeler yer almaktadır:

Tanrı Haldi'nin kudretiyle Ǐspuini oğlu Minua bir Haldi kapısı yaptırd ve Aludiri Şehri'nde kusursuz bir şekilde bir kale yaptırdl.

Tanrı Haldi'nin kudretiyle, İspuini oğlu Minua, tanrl Haldi'nin buyruğu üzerine babasinın tahtına oturduğu zaman, Šatiru Ülkesi ayaklandı. Tanrı Haldi kendi mızrağıyla sefere çıktı, Huradinaku Şehri'ni aldı, Gidimaru Şehri'ni ald v ve Šatiru Ülkesi'ni de aldl. Tanrı Haldi güçlü ve tanrı Haldi'nin mizrağı da güçlüdür.

Tanrı Haldi'nin kudretiyle İšpuini oğlu Minua sefere çıkt, Huradinaku Şehri'ni ve Gidamaru Şehri'ni ele geçirdi. Šatiru Ülkesi'ni ve Tarzu'anana Şehri'ni aldi. Buštu Ülkesi'ne ve Malmali Ülkesi'ne doğru ilerledi. Daha önce hiçbir kral Huradinaku Şehri'ni ele geçirememişti, hiç kimse onu yă̆ma edememişti. Tanrl Haldi onu İspuini oğlu Minua'ya verdi. O, Huradinaku Şehri'ni ele geçirdi ve yerle bir etti.

Aynı yıl Alzi Ülkesi'nde ayaklanma oldu. Tanrı Haldi sefere çıtı. İšpuini oğlu Minua için Qutume Şehri'ni yerle bir etti, Alzi Ülkesi'ni ele geçirdi ve Šašnu Ülkesi'ni ele geçirdi.

Qutume Şehri'nde bir kale yaptırdı. Tanr Haldi ... tanrt Teiseba, tanrı Sivini (ve bütün) dünyanın tanrları ... Ekilecek tarlalar ... bağlar ... Šurili Ülkesi'nde ... Minua'nın ...

\footnotetext{
${ }^{8}$ Yazıtlar hakkında geniș bilgi için bkz. Balkan, 1960: 133 vd.; Mellink, 1963: 183, no. 2; Mellink, 1965: 142, no. 2; Tasyürek, 1975: 153-154; Yıldırım, 1987: 454-455; Seidl, 1991: 80; Merhav-Ruder, 1992: 75-96; Salvini, 1991: 344-346; Payne, 2006: 73 vd.
} 
(Balkan, 1960: no. 1, res. 31-34; Melikișvili, 1971: no. 372; Payne, 2006: 73-74).

Kalede tespit ettiğimiz keramik verileri; İlk Tunç ve Orta Demir (Urartu) dönemlerine aittir.

\section{Giriktepe Höyüğü ${ }^{9}$}

Giriktepe Höyüğü, Ağrı ili, Patnos ilçesi, Çay Mahallesi'nin batı sınırlarında yer almaktadır. Höyük, $1640 \mathrm{~m}$ rakımda olup, zeminden $13 \mathrm{~m}$ yüksekliktedir (Foto. 2). Höyüğün doğu-batı doğrultulu uzunluğu $68 \mathrm{~m}$, kuzey-güney doğrultulu uzunluğu ise 49 m'dir. Höyügün güney tarafinda tarım arazileri mevcuttur ve küçük bir dere geçmektedir.

Höyükte, K. Balkan başkanlığında 1961-1962 yılları arasında bilimsel kazı çalışmaları yürütülmüştür. $\mathrm{Bu}$ çalışmalarda höyükte, iki mimari tabaka tespit edilmiştir. II. tabaka olarak isimlendirilen alan; mimari özellikleri, zengin madeni eserleri ve diğer buluntular dişında Urartu saray keramikleri bulunması bakımından oldukça önemlidir. II. tabakada tespit edilen binanın büyüklüğü, planı ve mimari özellikleri, büyük bir taht salonu, geniş iki mutfak odası, bir kiler, bir seramik deposu ve büyük küplerin dizili olduğu bir mahzene sahip olması, bu binanın Urartu sarayı olduğunu düşündürmektedir. Ayrıca bu tabakada bulunan keramik ve altın eserlerin Urartu sanatının nadir örneklerinden olması, binanın etrafının taştan kalın bir surla çevrilmesi de buranın saray olduğuna kanıt niteliğindedir (Balkan, 1964: 239 vd.; Kozbe-Ceylan vd. 2008: Giriktepe).

Höyükte gerçekleştirilen bilimsel kazıdan sonra birçok kaçak kazı yapılmıştır. Tespit edilen keramik verileri; Geç Kalkolitik, İlk Tunç (Karaz) ve Orta Demir (Urartu) dönemlerine tarihlendirilmektedir.

\section{Dizginkale Kalesi $\mathbf{I}^{10}$}

Ağrı ili, Patnos ilçesine bağlı Dizginkale Köyü'nün güneyinde yer almaktadır (Foto. 3). $2312 \mathrm{~m}$ rakıma sahip olan kalenin güneyinde Süphan Dağı bulunmaktadır. Urartu dönemine ait kalelerden biri olan Dizginkale I'in zeminden yüksekliği 97 m’dir. Kalenin, kuzey-güney yönünde uzunluğu $198 \mathrm{~m}$, doğu-batı doğrultusunda uzunluğu ise 155 m'dir.

Kale, anakaya özelliği bozulmadan anakayanın orta kısmı kullanılarak yapılmıştır. Kalede yer yer kalınlığı 3.60 m olan sur duvarları takip edilebilmektedir. Surlarda genellikle ön yüzü tıraşlanmış 120 x 40, 100 x 70,160 x $50 \mathrm{~cm}$ büyüklüğünde taşlar bulunmaktadır. Taşların arası küçük taşlarla doldurulmuştur. Kalenin girişini, batısından dönemeçli olarak güneyine doğru inen bir kap1 sistemi oluşturmaktadır. $\mathrm{Bu}$ sistem, savunmayı güçlendirmek amacıyla yapıımıştır. Batıya doğru açılan kapı doğuya doğru devam ederek oradan güneye ulaşır. Kalenin güney kesiminde baraj olabileceğini düşündüğümüz su kaynakları mevcuttur. Su kaynakları, tarla sulama ve yol yapımı sırasında tahrip edilmiştir. Günümüzde Dizginkale köyünün

${ }^{9} 0425241 \mathrm{D}-0391338 \mathrm{~K}$

${ }^{10} 4247392 \mathrm{D}-3859362 \mathrm{~K}$ içine bir baraj yapılmaktadır. Kalenin güneyinde mezarlık alanı bulunmaktadır. Kalede, çok sayıda kaçak kazı alanı mevcuttur. Kalenin içinde bir koridor bulunmaktadır. Derinliği $9.80 \mathrm{~m}$ olan koridorun girişi $2.21 \mathrm{~m}$, sonu ise $1 \mathrm{~m}$ genişliğindedir.

Kalede tespit edilen keramik verileri; İlk Tunç, Orta Demir (Urartu) ve Geç Demir Çağ 1 dönemlerine tarihlendirilmektedir.

\section{Dizginkale Kalesi II $^{11}$}

Ağrı ili, Patnos ilçesine bağlı Dizginkale köyünün 500 m batısında yer almaktadır (Foto. 4). Kalenin 600 m güneyinde Dizginkale Kalesi I bulunmaktadır. Kale 2263 m rakımda, zeminden $40 \mathrm{~m}$ yüksekliktedir. Kalenin kuzey-güney uzunluğu 163 m, doğu-batı genişliği ise 156 m'dir.

Kale, bulunduğu coğrafyaya hakim bir konumda yer almaktadır. Etrafı kayalıklarla çevrili olan kale, savunma açısından oldukça korunaklı bir yapıya sahiptir. Kale içerisinde, kaçak kazı çukurları tespit edilmiştir. Büyük boyutlu olan kaçak kazı çukurları, kalenin tarihi dokusuna zarar vermiştir.

Kalede tespit edilen keramik verileri İlk Tunç, Erken Demir, Orta Demir (Urartu), Geç Demir ve Orta Çağ'a aittir.

\section{Dizginkale Kalesi III ${ }^{12}$}

Ağrı ili, Patnos ilçesi, Dizginkale köyünde yer almaktadır (Foto. 5). Kale, Dizginkale Kalesi II'nin 300 m kuzeyinde bulunmaktadır. Kale, $2232 \mathrm{~m}$ rakıma sahip olup, zeminden 8 $\mathrm{m}$ yüksekliktedir. Kalede yer yer sur duvarları izlenebilmektedir. Kale, savunma açısından son derece önemlidir. Kalenin içinde bazı mimari bölümler tespit edilmiştir. Kalenin kuzey ucunda doğu-bat1 yönünde $36 \mathrm{~m}$, kuzey-güney yönünde ise 27 m'lik bir mimari yapı bulunur. Kalenin çevresinde su kaynakları mevcuttur. Hayvancılık için oldukça elverişli bir bölgedir. Günümüzde halen bölge halk1, hayvancılıkla geçimini sağlamaktadır.

Kalede, keramik verisine rastlanılmamıştır. Ancak kalenin, Dizginkale I ve Dizginkale II Kalelerine yakınlığı ve sahip olduğu mimari yap1 özelliklerine dayanarak, Dizginkale I ve Dizginkale II ile aynı dönemlerde var olduğunu ifade edebiliriz.

\section{Yalçınkaya Kalesi $I^{13}$}

Ağrı ili, Patnos ilçesinin yaklaşık olarak $3.5 \mathrm{~km}$ güneyinde, Yalçınkaya köyünün ise hemen kuzeyindeki kayalık tepede bulunur (Foto. 6). Zeminden $33 \mathrm{~m}$ yükseklikte yer alan kalenin rakımı 1668 m'dir.

Kale, kuzey-güney doğrultusunda $66 \mathrm{~m}$ uzunluğa, doğu-batı yönünde ise $26 \mathrm{~m}$ genişliğe sahiptir. Kalenin kuzey tarafi verimli tarım arazileri ile kaplıdır. Kale üzerinde, çapları $45 \mathrm{x}$

\footnotetext{
${ }^{11} 4247360 \mathrm{D}-3900036 \mathrm{~K}$

${ }^{12} 4247355 \mathrm{D}-3900114 \mathrm{~K}$

${ }^{13} 4250507 \mathrm{D}-2910457 \mathrm{~K}$
} 
$50 \mathrm{~cm}$ olan dört sunak mevcuttur. Kalenin kuzey ucundaki kayalık üzerinde 7 adet kaya basamağı izlenebilmektedir. Bu basamakların uzunluğu $1 \mathrm{~m}$, yüksekliği ve genişliği ise 40 cm'dir. Kalede çok sayıda kaçak kazı izi mevcuttur.

Kalede tespit edilen keramik verileri; Geç Kalkolitik, İlk Tunç, Orta Tunç, Orta Demir (Urartu), Helenistik ve Orta Çağ dönemlerine tarihlendirilmiştir.

\section{Yalçınkaya Kalesi $\mathbf{I I}^{14}$}

Ağrı ili, Patnos ilçesinin yaklaşık olarak $5 \mathrm{~km}$ güneyinde, Yalçınkaya köyünün ise $1.5 \mathrm{~km}$ doğusunda yer almaktadır (Foto. 7). Kale, $1730 \mathrm{~m}$ rakıma sahip olup, zeminden $64 \mathrm{~m}$ yüksekliktedir. Kalenin doğu-batı uzunluğu $86 \mathrm{~m}$, kuzeygüney genişliği ise 56 m'dir.

Kalenin etrafinda bulunan sur duvarlarının kalınlığı 2.80-2.90 $\mathrm{m}$ arasında değişmektedir. Sur duvarlarının en dik tarafi kalenin kuzey tarafındadır. Bu kısımdaki duvarın taşları, kalenin alt tarafina kadar yuvarlanmıştır. Sur duvar yapımında kullanılan taşların boyutları 100 x $90 \mathrm{~cm}, 90$ x 70 $\mathrm{cm}$ ve 130 × $75 \mathrm{~cm}$ arasında değişmektedir. Kalenin giriş kapısı doğu sur duvarında bulunmaktadır. Kapının eni 5.50 $\mathrm{cm}$, boyu ise $4.60 \mathrm{~cm}$ 'dir. Kalenin giriş kapısından girdikten sonra geniş bir alan mevcuttur. Kalenin kuzeybatısı ve batısı tarım arazileri ile kaplıdır. Köylülerden alınan bilgilere göre, kalenin doğusundaki nekropol alanı yol müteahhidine verilmiş ve iş makineleri ile tahrip edilmiştir. Bölgedeki en büyük kaçak kazı çalışmaları bu kalede meydana gelmiştir. Kalede, bölgedeki yerel yöneticiler tarafından acilen önlem alınmalıdır.

Kalede tespit edilen keramik verileri; İlk Tunç, Erken Demir ve Orta Çağ dönemlerine tarihlendirilmektedir (Foto. 8; Çizim 1). Ayrıca kalede, çok sayıda obsidiyen bulunmaktadır.

\section{Bozoğlak Kalesi ${ }^{15}$}

Ağrı ili, Patnos ilçesine bağlı Bozoğlak köyünün doğusunda yer almaktadır (Foto. 9). Kale, 1920 m rakımda, zeminden 45 m yükseklikte bulunmaktadır. Kalenin kuzey-güney uzunluğu $26 \mathrm{~m}$, doğu-batı uzunluğu ise 43 m'dir. Kale, stratejik bir konuma sahiptir. Kalenin doğusundan gelip köyün güneydoğusundan geçen kuru bir dere yatağı bulunmaktadır. Kalenin özellikle batısında sur duvarı kalıntıları izlenebilmektedir. Tepenin üstünde bulunan kayalık alan düzeltilmeden kullanılmıştır. Kalede çok sayıda kaçak kazı izi mevcuttur. Kalenin güney eteklerinde taşlı kısımda yılan motifi tespit edilmiştir.

Kale, savunma açısından elverişli bir konumda yer almaktadır. Kalenin güney ve doğu kesimi oldukça sarp kayalıklar ile kaplıdır. Bu kayalıklar kaleye doğal bir koruma özelliği sağlamaktadır. Kalenin doğu eteklerinde İlk Tunç Çağına ait nekropol alanı bulunmaktadır. Kalenin kuzeyinde ise Orta Çăg'a ait mezarlık tespit edilmiştir. Kalenin giriş kapısı batısında yer almaktadır.
Kalede yaptığımız incelemelerde; İlk Tunç, Erken Demir, Orta Demir (Urartu) ve Orta Çağ'a ait çok sayıda keramik verisi elde edilmiştir (Foto. 10; Çizim 2). Kale, aynı zamanda bir obsidiyen işleme merkezidir. Bunu kaledeki çok sayıdaki işlenmiş obsidiyen kalıntılarından anlamaktayız.

\section{Bozoğlak Nekropol Alanı ${ }^{16}$}

Ağrı ili, Patnos ilçesine bağlı Bozoğlak köyünün doğusunda yer almaktadır (Foto. 11). Nekropol alanı, $1900 \mathrm{~m}$ rakıma sahiptir. Bozoğlak Nekropol Alanı'nın batısında Bozoğlak Kalesi bulunmaktadır. Nekropol alanında İlk Tunç Çağı dönemine ve Karaz Kültürü'ne ait mezarlar mevcuttur. Mezarlık alanında çok sayıda kaçak kazı izi bulunmaktadır. Bu kaçak kazıların derinliği 1-1.5 m'ye kadar ulaşmaktadır. Kaçak kazılar neticesinde gün yüzüne çıkan çanak çömlek buluntuları tahrip edilmiştir. Mezarların bir kısmının oval planlı olduğu gözlemlenmiştir. Bölgede yaptığımız görüşmelerde pithoslar içerisinde ölü küllerinin bulunduğu ve bunların tahrip edildiği kayıtlarımıza geçmiştir. Mezarlık alanının kuzey kesiminde Orta Çağ'a ait bir mezarlık alanı daha mevcuttur. Bu Orta Çağ mezarlık alanında da çok sayıda kaçak kazı izi tespit edilmiştir. Nekropol alanında tespit edilen keramik verileri; İlk Tunç, Erken Demir, Orta Demir (Urartu), Geç Demir, Helenistik ve Orta Çă̆ dönemlerine aittir (Foto. 12; Çizim 3).

\section{Taşlıköy Obsidyen Yatağ ${ }_{1}^{17}$}

Ağrı ili, Patnos ilçesine bağlı Taşlıköy'ün hemen güneyinde yer almaktadır (Foto. 13). Bölgedeki kalelerde çok sayıda rastlanan işlenmiş obsidiyenlerin bu merkezden götürülmüş olması muhtemeldir. Obsidyen yatağı, oldukça geniş bir alana yayılmıştır. Önümüzdeki yıllarda, bu alanda obsidiyen çalışması planlanmıştır.

\section{Çatmaoluk Yerleşmesi ${ }^{18}$}

Ağrı ili, Patnos ilçesine bağlı Çatmaoluk köyünün $500 \mathrm{~m}$ doğusunda yer almaktadır (Foto. 14). Yerleşme alanı $2107 \mathrm{~m}$ rakımda bulunmaktadır. Günümüzde tarla olarak kullanılmakta olan yerleşme alanı, Süphan Dağı'nın kuzeydoğusunda yer almaktadır. Maalesef yerleşme, tarım arazisi olarak kullanılmak için tamamen tahrip edilmiştir. Tarım makinaları ile sürüldüğü için yerleşim yerleri tespit edilememiştir. Alanda yaptığımız incelemelerde çok sayıda keramik verisi elde edilmiştir. Yerleşmede tespit edilen keramik verileri; İlk Tunç, Erken Demir ve Orta Demir (Urartu) dönemlerine tarihlendirilmiştir. Yerleşmede, çok sayıda obsidiyen kalıntısına da rastlanılmıştır.

\section{Yukarı Kamışlı Nekropolï ${ }^{19}$}

Ağrı ili, Patnos ilçesine bağlı Yukarı Kamışlı köyünde, Yukarı Kamışlı Kalesi'nin yaklaşık 300 m batısında yer almaktadır (Foto. 15). Nekropol alanı, $1663 \mathrm{~m}$ rakımda bulunmaktadır. Nekropol alanında yapılan incelemelerde keramik bulunamamış ancak mezarlar tespit edilmiştir. Kale ile nekropol alanı arasında kesintisiz bir sur duvarı bulunmaktadır. Nekropol alanındaki incelemelerimiz akşam

\footnotetext{
${ }^{16} 4259060 \mathrm{D}-3914149 \mathrm{~K}$

${ }^{17} 4250202 \mathrm{D}-3902371 \mathrm{~K}$

${ }^{18} 4246036 \mathrm{D}-3900572 \mathrm{~K}$

${ }^{19} 4249272 \mathrm{D}-3908007 \mathrm{~K}$
} 
saati yaklaştığından dolayı önümüzdeki yıllarda devam edilmek üzere sonlandırılmıştır.

\section{Yukarı Kamıșlı Kalesii ${ }^{20}$}

Ağrı ili, Patnos ilçesine bağlı Yukarı Kamışlı köyünün batısında yer almaktadır (Foto. 16). Kale, 1698 m rakımda, zeminden $50 \mathrm{~m}$ yükseklikte bulunmaktadır. Kalenin doğubatı uzunluğu $132 \mathrm{~m}$, kuzey-güney genişliği ise $36 \mathrm{~m}$ 'dir. Alçak bir tepe üzerinde bulunan kalenin kuzey tarafı daha dik, güney tarafı ise daha yayvandır.

Köyün içme suyu deposu, kalenin bulunduğu tepede yer almaktadır. Kalenin dört tarafinda da sur duvarları izlenebilmektedir. Sur duvarlarındaki taşların ortalama boyutları 90 × 50, 150 × 70, 70 × 45 cm ölçülerindedir. Kalenin doğu tarafı tarım arazileri ile kaplıdır. Kalede kaçak kazı alanları mevcuttur. Kalenin yaklaşık $500 \mathrm{~m}$ batısında bir nekropol alanı bulunur.

Kalede tespit edilen keramik verileri İlk Tunç, Erken Demir ve Orta Çăg dönemlerine aittir (Foto. 17).

\section{Bağdişan Höyük ${ }^{21}$}

Ağrı ili, Patnos ilçesine bağlı Bağdişan Mahallesi'nde yer almaktadır (Foto. 18). Höyük, mahalle ile iç içe durumdadır. Günümüzde höyügün üzerine evler yapılmıştır. Höyük alanı yöre halkı tarafından bahçe ve tarla olarak kullanılmaktadır. Arazi, 20 dönüm civarındadır. Höyüğün güneyinden mahalle yolu geçmektedir. Kuzey tarafında ise Molla İbrahim köyüne giden yol bulunmaktadır. Höyük arazisi günümüzde şahıslara aittir.

Höyükte tespit edilen keramik verileri; Geç Kalkolitik, İlk Tunç, Erken Demir, Orta Demir (Urartu) ve Orta Çağ dönemlerine aittir.

\section{Molla İbrahim Höyük ${ }^{22}$}

Ağrı ili, Patnos ilçesine bağlı Molla İbrahim köyünde $1630 \mathrm{~m}$ rakımda yer almaktadır (Foto. 19). Günümüzde tarla olarak kullanılan höyük, tamamen tahrip edilmiştir.

Höyükte tespit edilen keramik verileri; İlk Tunç ve Orta Çağ dönemlerine aittir (Foto. 20; Çizim 4).

\section{Molla İbrahim Nekropolü ${ }^{23}$}

Ağrı ili, Patnos ilçesi, Molla İbrahim köyünde yer almaktadır (Foto. 21). Nekropol alanının $4.5 \mathrm{~km}$ güneydoğusunda Aznavurtepe Kalesi bulunmaktadır. Nekropolde çok sayıda kaçak kazı yapılmıştır. Burada yılan başlı bilezikler ve urneler bulunmuş olduğu ifade edilmiştir. Patnos ilçesine giden yolun kuzeyinde höyük, höyüğün batısında ise nekropol alanı bulunur. Mezarlık günümüzde tarla olarak kullanılmaktadır. Nekropolün Aznavurtepe Kalesi'ne yakınlığı ve kaçak kazılar neticesinde ele geçirilen eserler göz önünde bulundurulduğunda, Orta Demir Çağı'na (Urartu) ait olduğunu ifade edebiliriz.

Çay Mahallesi Yerleșmesi ${ }^{24}$

Ağrı ili, Patnos ilçesine bağlı Çay Mahallesi'nde yer almaktadır (Foto. 22). Yerleşme, $1640 \mathrm{~m}$ rakımda bulunmaktadır. Yerleşmenin etrafı geniş bahçeleri olan evlerle çevrilmiştir. Yerleşme alanı günümüzde köy halkı tarafindan tarım arazisi olarak kullanılmaktadır. Arazinin sürekli işlenmesi sonucu birçok keramik verisi gün yüzüne çıkmıştır. Alanda obsidiyen verisi de bulunmaktadır.

Yerleşmede tespit edilen keramik verileri; Geç Kalkolitik, İlk Tunç (Karaz), Erken Demir, Orta Demir (Urartu), Geç Demir ve Orta Çăg dönemlerine aittir.

\section{Hisar Kalesi ${ }^{25}$}

Ağrı ili, Patnos ilçesine bağlı Hisar köyünün $300 \mathrm{~m}$ kuzeydoğusunda yer almaktadır (Foto. 23). Kale, $1860 \mathrm{~m}$ rakımda bulunmakta olup, kalenin zeminden yüksekliği 80 m'dir. Kalenin kuzeydoğu-güneybatı uzunluğu $65 \mathrm{~m}$, kuzeybat1-güneydoğu genişliği 42 m'dir. Kalenin girişi güneybatısında yer almaktadır. Ana kayalar kesilerek kaleye giriş kap1 açıklığ yerleşimin, güneydoğusu ile kuzeybatısı arasında olduğunu düşünüyoruz. Yolun sonunda nöbetçilerin dinlenebilesi için oyularak bir alan oluşturulmuştur. Bu alanın hemen batısında bir niş bulunur. Kalenin kuzeydoğundaki niş, $110 \mathrm{~cm}$ uzunluğunda $30 \mathrm{~cm}$ derinliğinde ve $30 \mathrm{~cm}$ yüksekliğindedir.

Kalenin kuzeybatı eteğinde açık hava tapınağı mevcuttur. Bu alanda kaya basamakları ve nişler yer almaktadır. Kalenin kuzeybatısından gelen kuru dere yatağı ile güneydoğusundan gelen kuru dere yatağ 1 , kalenin ön tarafında birleşmektedir. Kale savunmaya elverişli bir konumdadır. Kalenin alt tarafları tarım açısından uygundur. Kalenin özellikle Urartu döneminde yoğun olarak kullanıldığını düşünmekteyiz.

Kalede tespit edilen keramik verileri İlk Tunç, Erken Demir, Orta Demir (Urartu) ve Orta Çă̆ dönemlerine tarihlendirilmektedir.

\section{Hisar Kaya Altı Sığınağı ${ }^{26}$}

Ağrı ili, Patnos ilçesine bağlı Hisar köyünün $650 \mathrm{~m}$ kuzeydoğusunda yer almaktadır. Kaya altı Sığınağı, Hisar Kalesi'nin $350 \mathrm{~m}$ kuzeybatısında, $1860 \mathrm{~m}$ rakımda bulunmaktadır. Yerleşmenin zeminden yüksekliği 80 m'dir. Sığınağın, Prehistorik dönemde kullanıldığı düşüncesindeyiz. Sığınağın batı kısmı kesilerek bir oluk oluşturulmuştur. Yine batısında bulunan kayalık alanda her iki tarafı açık bir alan mevcuttur. $\mathrm{Bu}$ yerleşim yerinin kuzeybatı tarafı daha dar, güneybatı tarafı daha geniştir. Yapılan kaçak kazılarda buradaki taşların kırıldığı tespit edilmiştir. Alanın Prehistorik dönem açısından incelenmesi gerekmektedir.

\footnotetext{
${ }^{20} 4249408 \mathrm{D}-3808016 \mathrm{~K}$

${ }^{21} 0424941 \mathrm{D}-0039132 \mathrm{~K}$

${ }^{22} 0424916 \mathrm{D}-0391250 \mathrm{~K}$

${ }^{23} 0424914$ D - $0391257 \mathrm{~K}$
} 


\section{SONUC}

Patnos ve çevresi, Kalkolitik Çağ'dan itibaren yerleşim yeri olarak tercih edilmiştir. Bölgede, geçmişten günümüze kadar önemli yüzey araştırmaları ve bilimsel kazı çalışmaları gerçekleştirilmiş olmasına rağmen, bu çalışmalar uzun soluklu olmadığı için bölge tarihinin aydınlatılmasında yetersiz kalmıştır. Bu açıklığı gidermek maksadıyla bölgede, Kültür ve Turizm Bakanlığı'nın da izinleriyle tarafımızdan 2019 yılından itibaren yüzey araştırması yapılmaktadır.

2019 yılında, başkanlığını yaptığım ekip tarafından gerçekleştirilen yüzey araştırmaları oldukça verimli geçmiş, 19 sit ve 1 anıt alanında incelemelerde bulunulmuştur. Yapılan bu araştırma neticesinde, merkezlerin Geç Kalkolitik Çağ'dan itibaren yerleşim gördüğü tespit edilmiştir. Ayrıca bu merkezlerde bulunan keramik verileri, bölgenin İlk Tunç Çağı'nda yoğun bir yerleşime sahne olduğunu göstermektedir. Yine bölge, Urartu Krallığı döneminde de yoğun bir yerleşim görmüştür. Hem yüzey araştırmalarında tespit edilen keramik verileri, hem arkeolojik merkezlerin mimari yapıları, hem de bölgede geçmişten günümüze kadar tespit edilen Urartu Yazitları bu durumu kanıtlar niteliktedir. Bölge, Urartu Krallığ 1 tarafindan oldukça önemsenmiş ve krallığın kuruluş yıllarından itibaren bölgede imar faaliyetleri yürütülmüştür. 1957 yılında tespit edilen, 1961-1963 yılları arasında bilimsel kazı çalışmaları yürütülen ve 2019 yılında ise tarafimızdan incelemelerde bulunulan Aznavurtepe Kalesi, Urartu Krallığı'nın bölgedeki en önemli kalelerinden biri konumundadır. Kalede bulunan Urartu yazıtları da, bölgenin Eskiçağ Tarihi'ne 1şık tutması bakımından oldukça önemlidir.

Merkezlerde, çok sayıda kaçak kazı yapılması neticesinde yoğun tahribat oluştuğu görülmüştür. Bölgede yerel yöneticiler tarafından gerekli önlemler alınmadığı müddetçe, binlerce yıldır varlığını koruyan ve tarihe 1şık tutan arkeolojik merkezler, kaçak kazılar sebebiyle yok olmaktan kurtulamayacaktır. 


\section{KAYNAKCA}

Arsebük, G. (1974), Altınova'da Koyu Yüzlü Açkılı ve Karaz Türü Çanak Çömlek Arasındaki İlişkiler Sorunu, (Yayımlanmamış Doktora Tezi), İstanbul: İstanbul Üniversitesi.

Arsebük, G. (1986), “Altınova'da (Elazığ) Başlangıcından İlk Tunç Çağının Sonuna Kadar Kültürel Silsilesi ve Sosyal Tabakalanma

Sorunu”, Türk Tarih Kongresi Bildirileri 9, 67-72.

Balkan, K. (1960), "Patnos Yakınında Anzavurtepe'de Bulunan Urartu Tapınağı ve Kitabeleri”, Anatolia V, Ankara, 133-158.

Balkan, K. (1964), "Patnos’ta Keşfedilen Urartu Tapınă̆1 ve Urartu Sarayı”, Atatürk Konferansları I, Ankara, 235-248.

Baştürk, M. B. (2013), "Urartu Devletinin Kurucuları Üzerine: Labturi ?=? Lutibri. 35 Yıl Sonra, Yeniden”, Tarhan Armağanı, M.

Taner Tarhan'a Sunulan Makaleler, Essays in Honour of M. Taner Tarhan. Oğuz Tekin - Mustafa H. Sayar - Erkan Konyar (Ed.), İstanbul, 69-79.

Belck, W. - Lehmann, C. F. (1900a), "Bericht über die armenische Forschungsreise der H. Hrn. W. Belck und C. F. Lehmann", VBGAEU 32, 29-66, 430-439.

Belck, W. - Lehmann, C. F. (1900b), "Bericht über die Ergebnisse der von Dr. W. Belck und Dr. C. F. Lehmann 1898/99 ausgeführten Forschungsreise in Armenien", Sitzungsberichte der Könglich Preussischen Akademie der Wissenschaft: 619-639.

Burney, C. A.; Lawson, G. R. J. (1960), "Measured Plans of Urartian Fortresses", Anatolian Studies 10, 177-196.

Ceylan, A. (1994), Eski Anadolu Devletler Arası İlişkiler, Antlaşmalar (II. ve I. Binde), (Yayımlanmamış Doktora Tezi), Erzurum: Atatürk Üniversitesi Sosyal Bilimler Enstitüsü.

Ceylan, A. (2008), Doğu Anadolu Araştırmaları I, Erzurum-Erzincan-Kars-Iğdır (1998-2008), Erzurum.

Ceylan, A. (2015), Doğu Anadolu Araştırmaları II, Erzurum-Erzincan-Kars-Iğdır (2008-2014), Erzurum.

Ceylan, A.; Günaşdı, Y. (2017), "Erzurum ve Çevresindeki Urartu Yazıtlarının Tarihi Açıdan Değerlendirilmesi”, Akademik Tarih ve Düşünce Dergisi 4/13, 313-350.

Ceylan, A.; Günaşdı, Y. (2018), Erzurum'un Eskiçağ Kaleleri, Erzurum.

Ceylan, A.; Kalmış, G. (2019), “Sürmeli Çukuru'nda Önemli Bir Merkez; Suveren Kalesi ve Yerleşmeleri”, Kafkas Üniversitesi Sosyal Bilimler Enstitüsü Dergisi, 24, 619-634.

Ceylan, A.; Özgül, O. (2016), "Erzincan ve Çevresinde Urartular”, Uluslararası Erzincan Sempozyumu, 127-147.

Ceylan, A.; Özgül, O.; Kalmış, G. (2019), "Karaz Kültürü’nün Kahramanmaraş ve Çevresindeki Yansımaları”, Uluslararası Antik

Çă̆ Döneminde Maraş Sempozyumu, 26-52.

Ceylan, N. (2016), "Pasin Ovasının Kuzeye Açılan İki Tarihi Yolu”, Uluslararası Sosyal Araştırmalar Dergisi 9/43, 656-671.

Ceylan, N. (2019), "Çayırlı Tarihine Işık Tutan Yerleşme: Saygılı Höyük”, Kafkas Üniversitesi Sosyal Bilimler Enstitüsü Dergisi,

24, 635-648.

Erzen, A. (1992), Doğu Anadolu ve Urartular, Ankara.

Günaşd, Y. (2016), “Geçitler Ülkesinde Önemli Bir Urartu Kalesi: Avnik”, TÜBA-AR 19, 113-136.

Güterbock, H. G. (1963), "Urartian Inscriptions in the Museum of Van”, Journal of Near Eastern Studies 22, 268-272.

Hulin, P. (1958), "Urartian Stones in the Van Museum", AS 8, 235-244.

Hyvernat, H. (1892), "Inscriptions inedites", P. Müller-Simonis (ed.), Relation des missions scientifiques de MM. H. Hyvernat et P. Müller-Simonis (1888-1889), Paris-Lyons-Washington, 560-565.

Kalmış, G. (2019), “Erzurum'da Önemli Bir Tunç Çağı Merkezi: Aşkale Höyük”, Akademik Tarih ve Düşünce Dergisi 6/4, 20282053.

Kalmış, G. (2020a), “Yeni Veriler Işı̆̆ında Ardahan İlinin Eskiçağ Tarihi”, Türk Kültürüne Hizmet: Sadiddin Öztürk’e Armağan, 81-

110.

Kalmış, G. (2020b), “Kuzeydoğu Anadolu Bölgesinde Tespit Edilen Köroğlu Kaleleri”, Tokat Gaziosmanpaşa Üniversitesi Sosyal Bilimler Araştırmaları Dergisi XV/I, 155-169.

Karageçi, M. (2014), “Arpaçay Havzası'nda Tunç Çağı Yerleşmeleri”, Kafkas Üniversitesi Sosyal Bilimler Enstitüsü Dergisi 14, 77 -

95.

Karageçi, M.; Günaşdı, Y. (2019), "Erzurum’da Önemli Bir Urartu Kalesi: Harami Kale”, Kafkas Üniversitesi Sosyal Bilimler Enstitüsü Dergisi 24, 649-667.

Kocaman, S.; Kaya, F. (2014), Ağrı İlinin Turizm Coğrafyası, Erzurum.

Kozbe, G.; Ceylan, A. vd. (2008), Türkiye Arkeolojik Yerleşmeleri-6 Demir Çağları 1-2, İstanbul.

König, F. W. (1955), "Die Keilinschrifte von Patnos”, WZKM 52, 288-303.

König, F. W. (1955-57), Handbuch der chaldischen Inschriften, Archiv Für Orientforschung Herausgegeben Von Ernst Weidner,

Beiheft 8, Graz.

Lehmann-Haupt, C. F. (1928-35), Corpus Inscriptionum Chaldicarum, Berlin, Leipzig.

Maisler, B. - Stekelis, M. vd. (1952), “The Excavations at BethYerah (Khirbet el-Kerak) 1944-1946”, Israel Exploration Journal Volume 2, 165-173.

Melikişvili, G. (1960), Urartskie Klinoobraznye Nadpisi, Moskova.

Melikişvili, G. (1971), “Urartskie Klinoobraznye Nadpisi 2: Otkritiya i Publikatsiyi 1954-1970gg”, VDI 3: 227-255; 4: $265-294$.

Mellink, M. J. (1963), “Archaeology in Asia Minor”, American Journal of Archaeology 67, 173-190.

Mellink, M. J. (1965), “Archaeology in Asia Minor”, American Journal of Archaeology 69, 133-149.

Merhav, R.; Ruder, A. (1992), "The Construction and Production of a Monumental Bronze Candelabrium of King Menua of Urartu", (Ed. A. Çilingiroğlu-D. H. French), Anatolian Iron Ages - The Proceedings of the Second Anaolian Iron Ages Colloquium Held at Izmir 4-8 May 1987, Ankara, 75-96.

Morkoç, A. N. (2020a), “Erzurum İli Palandöken İlçesi Höyük ve Yerleşmeleri”, Kafdağı 5/1, 98-120.

Morkoç, A. N. (2020b), “Kuzeydoğu Anadolu'da Önemli Bir Yerleşme-Danamayalı”, Gaziosmanpaşa Üniversitesi Sosyal Bilimler Araştırmaları Dergisi 2020 Sonbahar Özel Sayı I/I, 64-76. 
Morkoç, A. N. (2020c), “Erzurum’da Önemli Höyükler: Gökçeşeyh Höyük I-II”, 2. Uluslararası Multidisipliner Sosyal Bilimler Kongresi, 240-270.

Özgül, O. (2011), “Eskiçağ' da Narman Havzası”, Kafkas Üniversitesi Sosyal Bilimler Enstitüsü Dergisi 7, 97-114.

Özgül, O. (2016), “Erzurum’da Stratejik Bir Urartu Kalesi: Tepeköy (Pir Ali Baba)”, TÜBA-AR 19, 137-157.

Payne, M. R. (2006), Urartu Çivi Yazılı Belgeler Kataloğu, İstanbul.

Pehlivan, M. (1990), “Karaz ve Hurriler”, Yüzüncü Y1l Üniversitesi Fen-Edebiyat Fakültesi Sosyal Bilimler Dergisi 1/1, 168-175.

Pehlivan, M. (1991), Daya(e)ni / Diau(e)hi (Uruatri-Nairi Konfederasyonları Döneminden Urartu'nun Yıkılışına Kadar), Erzurum.

Piotrovskii, B. B. (1962), "The Aeneolithic Culture of Trans-Caucasian in the Third Millennium B.C.", VI. International Concress of Prehistori cand Proto historic Sciences, Moscow, 7.

Sagona, A.; Zimansky, P. (2015), Arkeolojik Veriler Işı̆ğında Türkiye’nin En Eski Kültürleri (M.Ö. 1.000.000-550), İstanbul.

Salvini, M. (1967), Nairi e Ur(u)atri: Contributa alla Storia della Formazione del regno di Urartu, Roma.

Salvini, M. (1991), "Una nuova iscrizione urartea", Orientalia 60, 344-346.

Salvini, M. (2006), Urartu Tarihi ve Kültürü, İstanbul.

Sandalgian, J. (1900), Les inscriptions cunéiformes Urartiques: transcrites avec une triple traduction interlinéaire en Arménien classique, en Latin et en Française, suivies d'un glossaire et d'une grammaire, Venedik.

Sayce, A. H. (1893), "The Cuneiform Inscriptions of Van, part 4”, JRAS 25, 1-39 (no. 69-79).

Seidl, U. C. (1991), "Chariot and Horse Fittings: Horse Trappings", (Ed. R. Merhav), Urartu, A Metalworking Center in the First Millenium B. C. E. Yeruşalem, 116-122.

Tarhan, M. T. (1978), M.Ö. XIII. Yüzyılda "Uruatri” ve "Nairi” Konfederasyonları, (Yayımlanmamış Doçentlik Tezi), İstanbul: İstanbul Üniversitesi Edebiyat Fakültesi.

Tarhan, M. T. (1982), "Urartu Devletinin Kuruluş Evresi ve Kurucu Krallardan "Lutupri=Lapturi” Hakkındaki Yeni Görüşler”, Anadolu Araştırmaları VIII, İstanbul, 69-114.

Taşyürek, O. A. (1975), “Some Inscribed Urartian Bronze Armour”, Iraq 37/2, 151-155.

Üngör, İ. (2018a), “Urartu Devleti’nin Kuzey Bölgesinde Önemli Bir Kale: Tuzla Kalesi”, Akademik Tarih ve Düşünce Dergisi 5/17, 93-129.

Üngör, İ. (2018b), “Yeni Araştırmalar Işığında Erzincan'ın Eskiçağ Tarihi”, XVII. Türk Tarih Kongresi I, Ankara, 207-233.

Üngör, İ. (2019), "Kuzeydoğu Anadolu’da Önemli Bir Demir Çağı Merkezi: Polat Kalesi (Kars/Arpaçay)", Kafkas Üniversitesi Sosyal Bilimler Enstitüsü Dergisi, 24, 755-770.

Van Loon M. N. (1966), Urartian Art Its Distinctive Traits in the Light of New Excavations, İstanbul.

Yazgan, Ş.; Kadanalı, E. (2012), “Ağrı İlinin Kırsal Turizm Potansiyelinin Değerlendirilmesi”, Karamanoğlu Mehmetbey Üniversitesi Sosyal ve Ekonomik Araştırmalar Dergisi 14/22, 5-10.

Yildırım, R. (1987), “Urartu At Gemleri / Urartaische Trensen”, Belleten 51/200, 441-496.

Yıldız, M. Z. (1996), Patnos'un Şehir Coğrafyası, (Yayımlanmamış Yüksek Lisans Tezi), Erzurum: Atatürk Üniversitesi Sosyal Bilimler Enstitüsü. 


\section{EXTENDED ABSTRACT}

Patnos district occupies an area of $1.420 \mathrm{~km}^{2}$ and is about $7.9 \%$ of the provincial territory. In the north of the district are the Tutak and Hamur districts of Ağn province, in the west is the Malazgirt district of Muş, to the south and southeast is the Adilcevaz district of Bitlis, and in the east there is the Erciş district of Van. Patnos is located on the Patnos Plain, which is spread over a large area $\left(a b o u t 230 \mathrm{~km}^{2}\right)$. The potential for agriculture and livestock of the plain is quite high. The Plaing whose altitude ranges from 1620-1670 m, is located between Aladağlar in the north and Mount Süphan in the south.

It is possible to express that the first settlements in Patnos and its surroundings date back to the Late Chalcolithic Age. In the region, since the second half of the nineteenth century B.C., Karaz Culture, which has spread to a wide geography up to Transcaucasia, Northwest Iran, Amik Plain, Northern Syria and Palestine, Eastern Anatolia Region being the center, has been influential. The Culture stands out with its architectural features and unique stoneware. It is known that there was a dense settlement in the region during this due to surface exploration and scientific excavation studies carried out from past to present.

Along with the withdrawal of the Hurri-Mitanni Community from the historical stage, tribes with Hurri origin and the communities related to them in the Eastern Anatolia region gathered around the governors. These communities living in the high plateaus of Eastern Anatolia, formed the "Uruatri-Nairi" confederation that ruled between the XIII-IX centuries BC. This period was named by scientists with more than one name such as "The Proto History of Urartian" or "The Anathic Age of Urartian".

At the end of the period of the Uruatri-Nairi confederations, the governors were united under the name of Urartian State, providing togetherness against their powerful enemy Assyria. Numerous inscriptions, castles and settlements have been determined in and around Patnos belonging to Urartian, which has a very important place in the Ancient History of the Eastern Anatolia region. Scientific excavations were carried out at Aznavurtepe Castle and Giriktepe Mound in the district. As a result of these excavations, the structures built in the architectural style of Urartian and the ruins of the fortification walls were discovered. In addition, the rich Urartian palace materials were found in Giriktepe Moun show the importance of this center for the Urartian State. Based on the richness of the Urartian heritage in the region, it is possible to state that the region had great importance for the Urartian State during this period.

Patnos and its surroundings have been preferred as settlements by people since the Chalcolithic Age. Although important surface surveys and scientific excavations have been carried out in the region from the past to the present, these studies have been inadequate in terms of illuminating the history of the region since they were not long-term. In order to eliminate this gap, surface excavations have been carried out by us in the region since 2019 with the permissions of the Ministry of Culture and Tourism.

In 2019, the surface excavations carried out by the team headed by me were very efficient and excavations were carried out in 19 sites and in 1 memorial area. As a result of this research, it was determined that the centers were settled since the Late Chalcolithic Age. In addition, stoneware data found in these centers show that the region was the scene of a dense settlement in the First Bronze Age. Again, the region was also heavily instituted during the period of the Kingdom of Urartian. Both the stoneware data detected in surface surveys, the architectural structures of archaeological centers and the Urartu Inscriptions detected in the region from the past to the present prove this situation. The region was very important for the Kingdom of Urartian and zoning activities were carried out in the region since the founding years of the kingdom. Aznavurtepe Castle, which was discovered in 1957, scientific excavations were carried out between 1961-1963 and examined by us in 2019, is one of the most important castles of the Urartian Kingdom in the region. Urartian inscriptions in the castle are also very important since they shed light on the ancient history of the region.

It has been observed that there had been intense destruction in the centers as a result of numerous illegal excavations. Unless necessary measures are taken by local authorities in the region, archaeological centers, which have been preserved for thousands of years and shed light on history, will be destroyed due to illegal excavations. 
FOTOĞRAFLAR

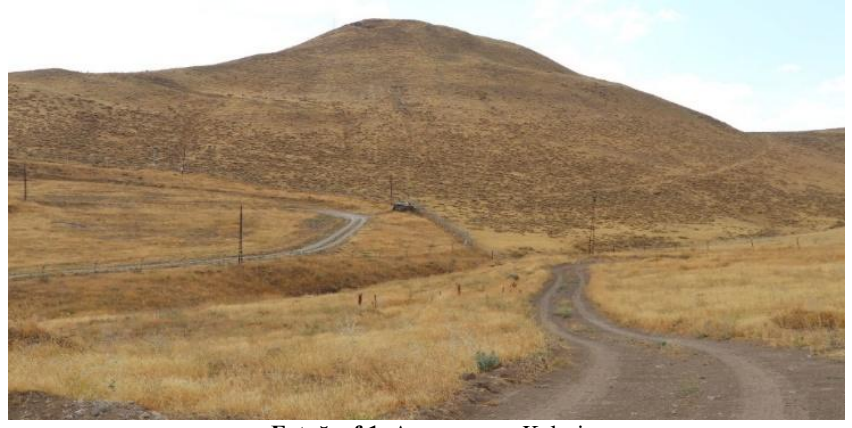

Fotoğraf 1. Aznavurtepe Kalesi

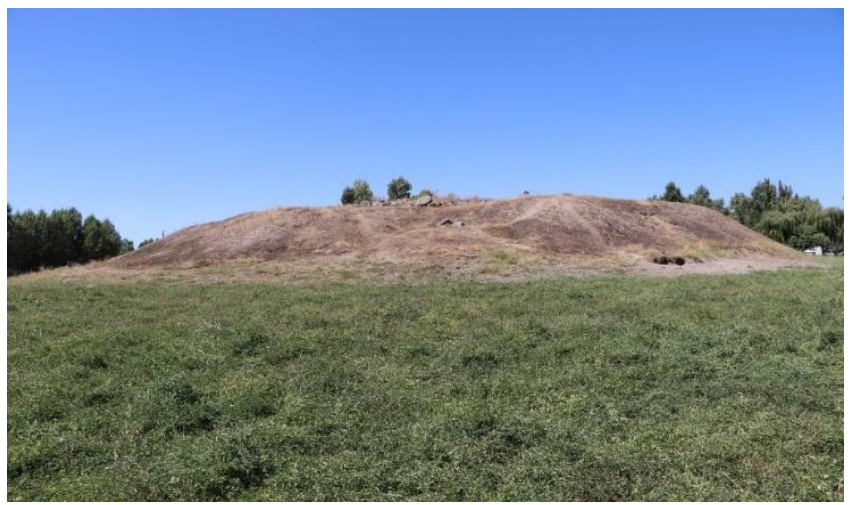

Fotoğraf 2. Giriktepe Höyüğü

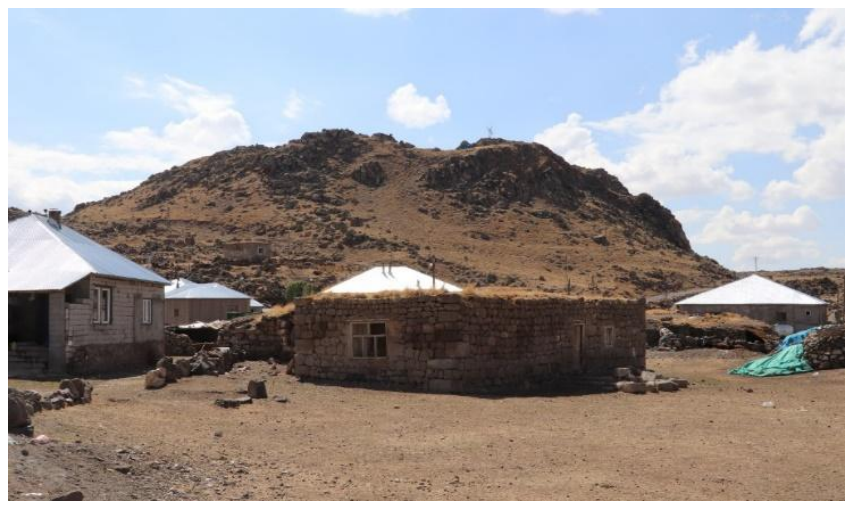

Fotoğraf 3. Dizginkale Kalesi I

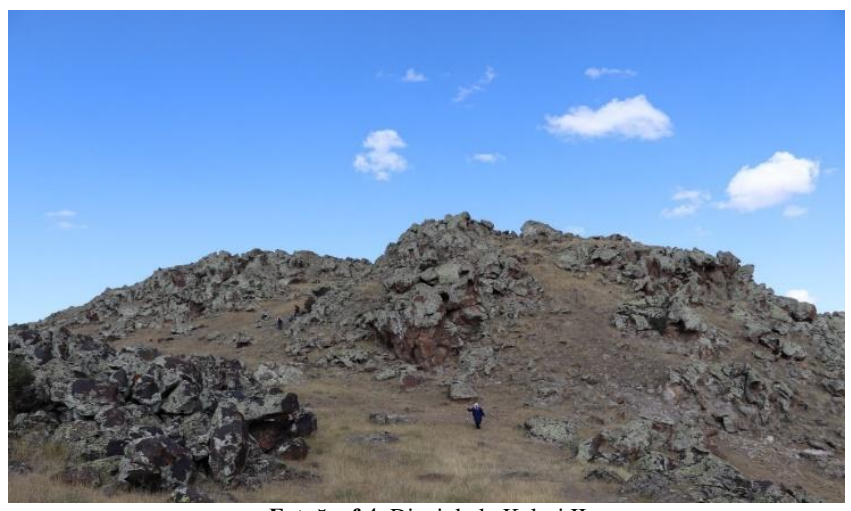

Fotoğraf 4. Dizginkale Kalesi II
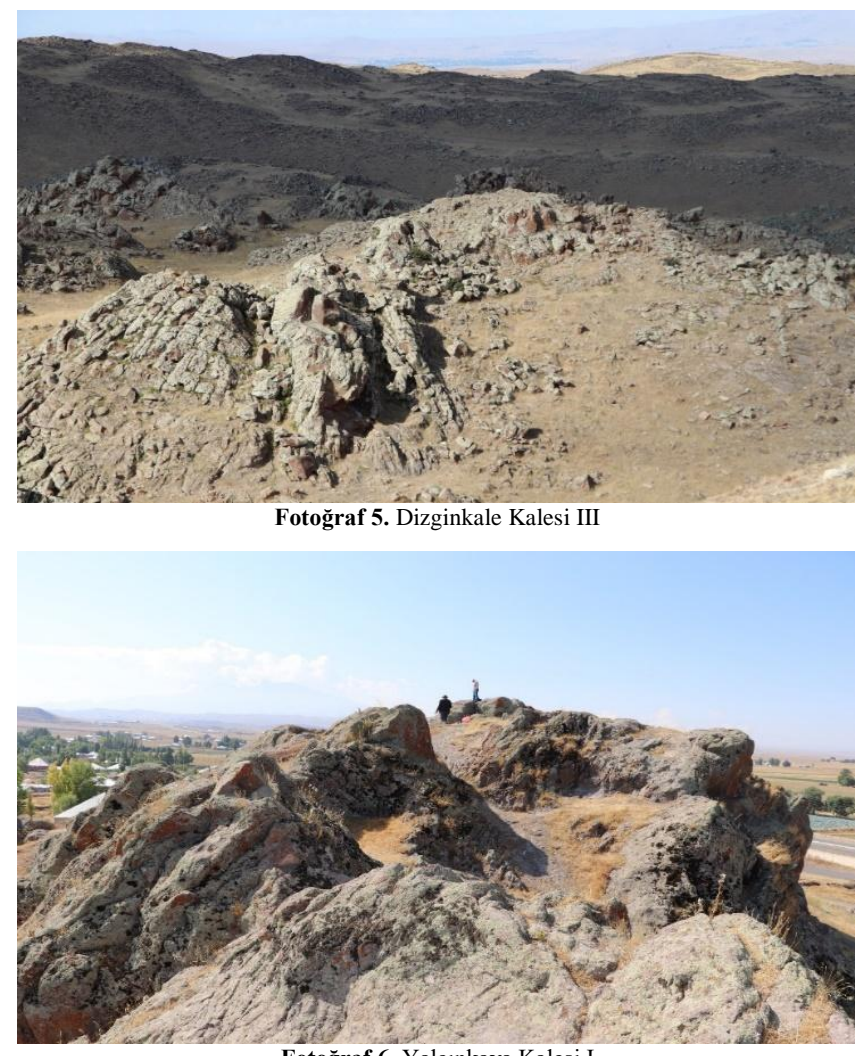

Fotoğraf 6. Yalçınkaya Kalesi

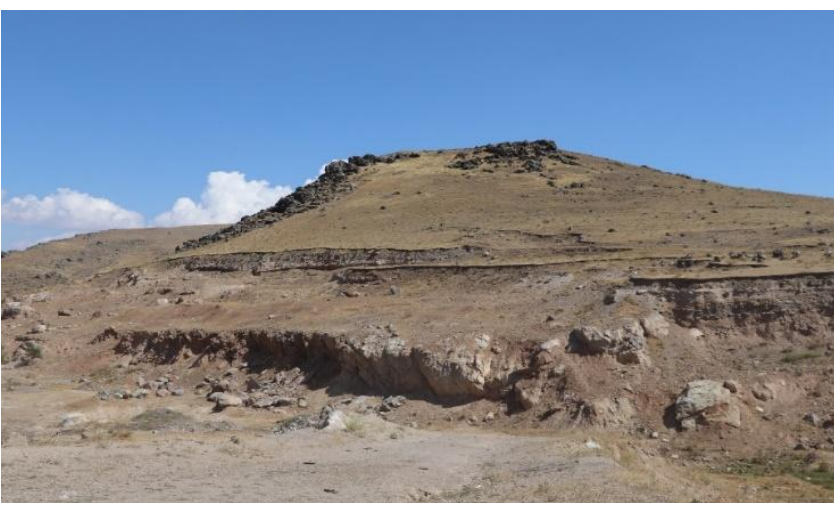

Fotoğraf 7. Yalçınkaya Kalesi II

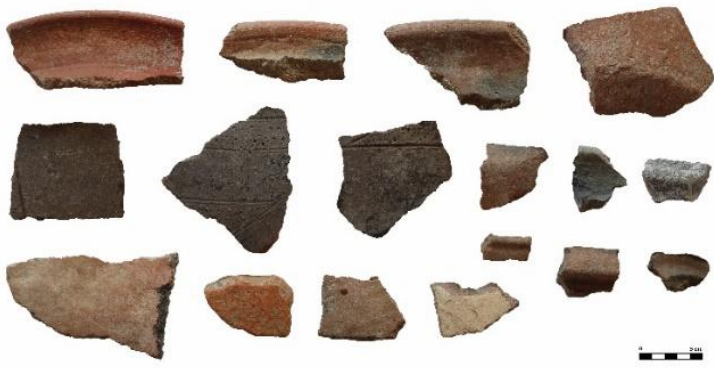

Fotoğraf 8. Yalçınkaya Kalesi II Keramik Fotoğrafları 


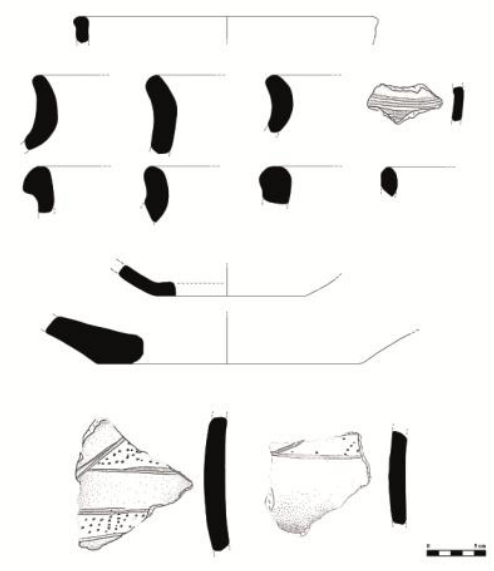

Çizim 1. Yalçınkaya Kalesi II Keramik Çizimleri

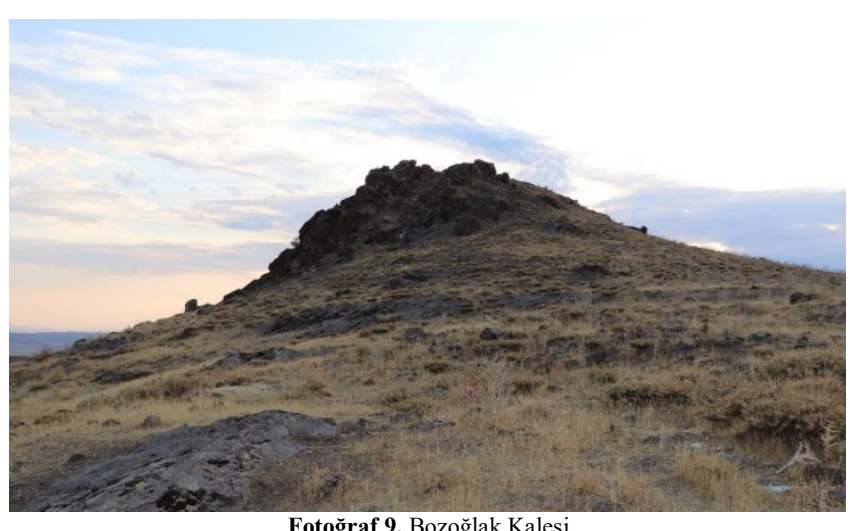

Fotoğraf 9. Bozoğlak Kalesi

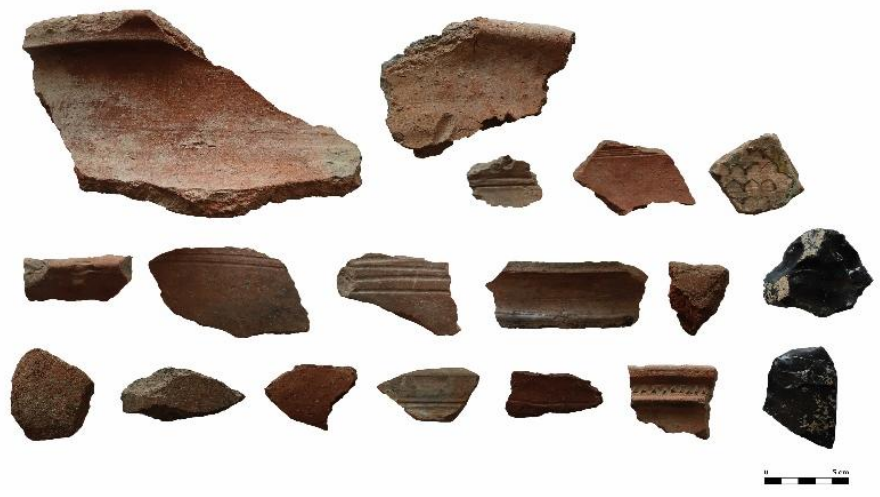

Fotoğraf 10. Bozoğlak Kalesi Keramik Fotoğrafları
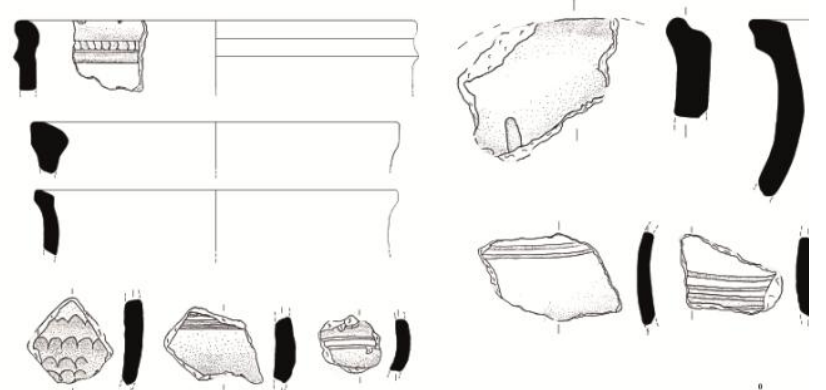

$=$
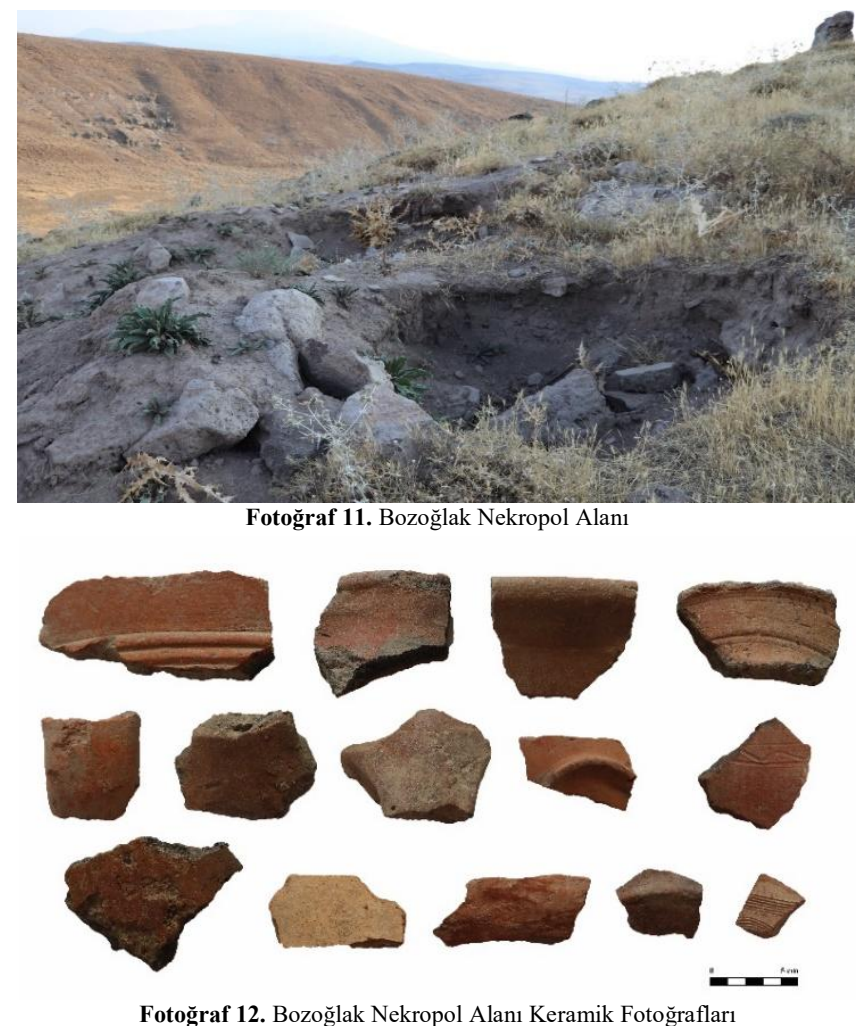

Fotoğraf 12. Bozoğlak Nekropol Alanı Keramik Fotoğrafları

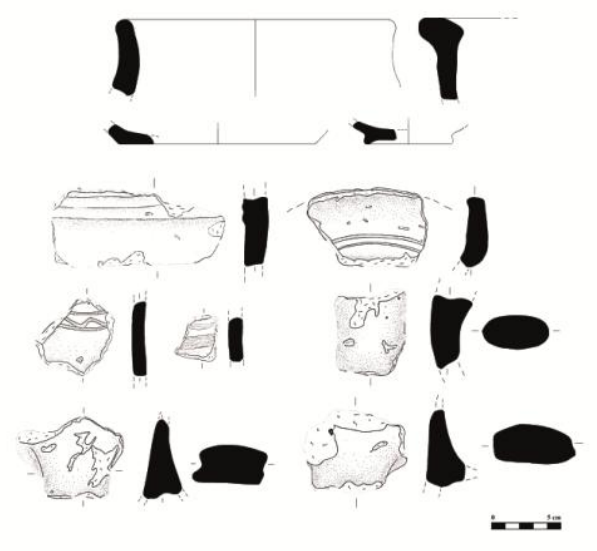

Çizim 3. Bozoğlak Nekropol Alanı Keramik Çizimleri

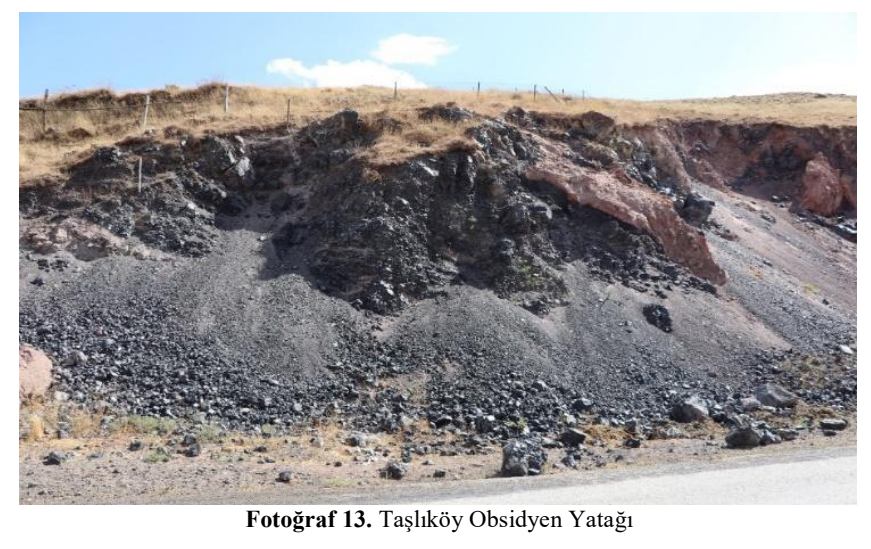

Çizim 2. Bozoğlak Kalesi Keramik Çizimleri 


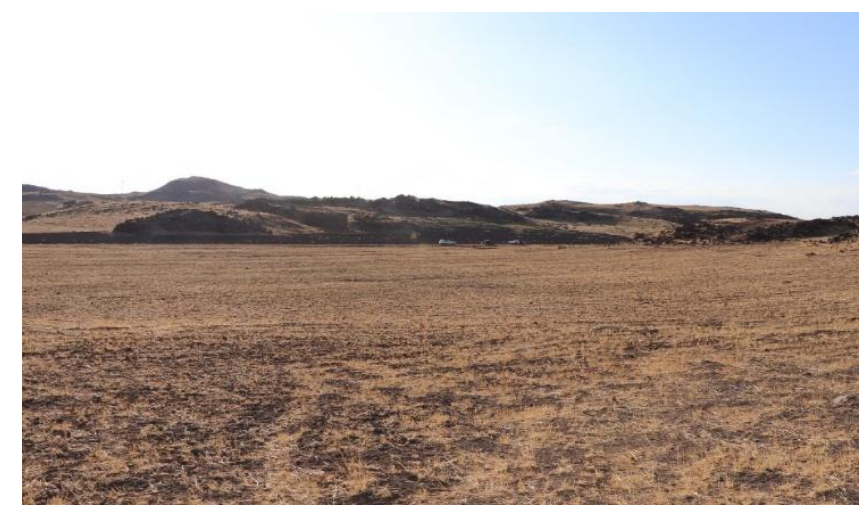

Fotoğraf 14. Çatmaoluk Yerleşmesi

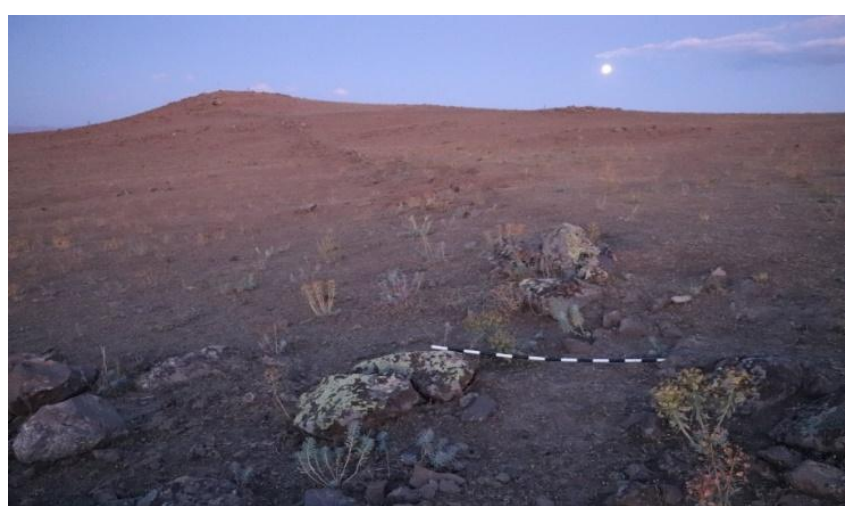

Fotoğraf 15. Yukarı Kamışlı Nekropolü

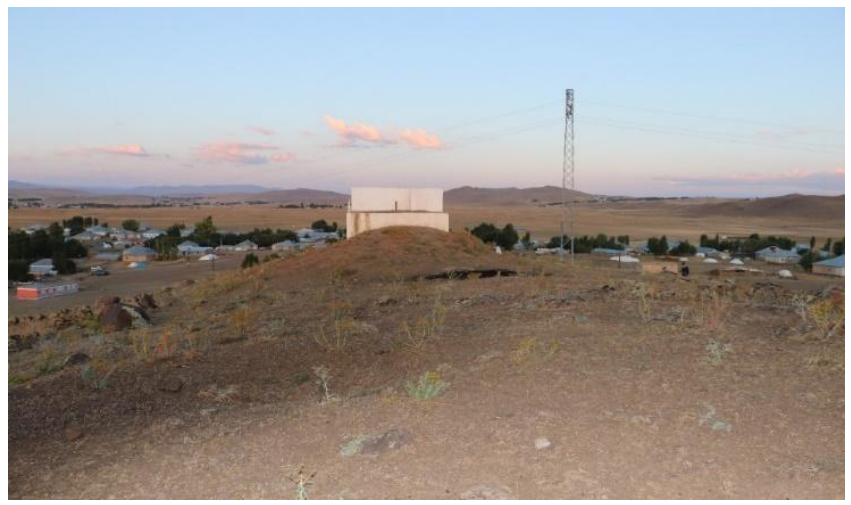

Fotoğraf 16. Yukarı Kamışlı Kalesi

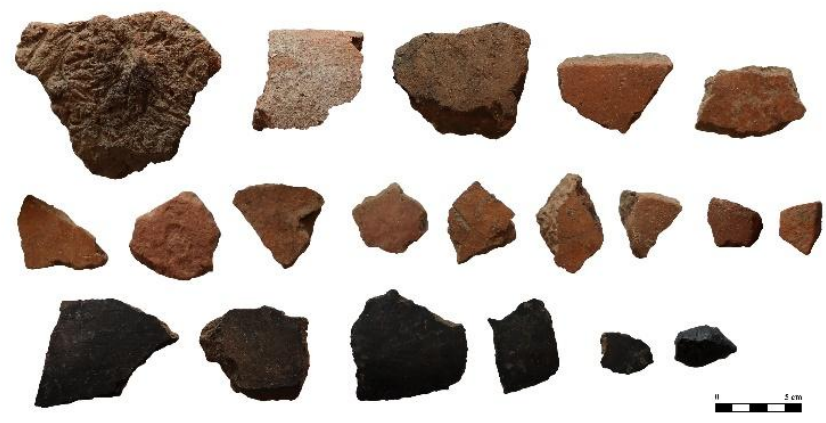

Fotoğraf 17. Yukarı Kamışlı Kalesi Keramik Fotoğrafları

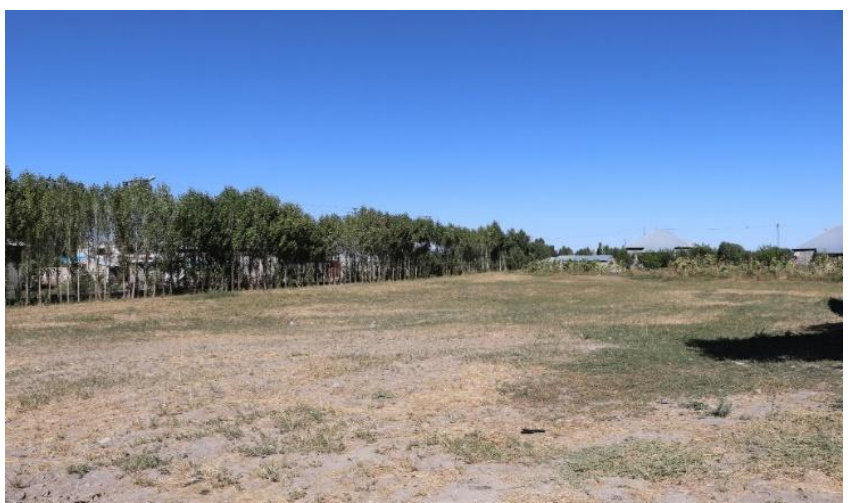

Fotoğraf 18. Bağdișan Höyük

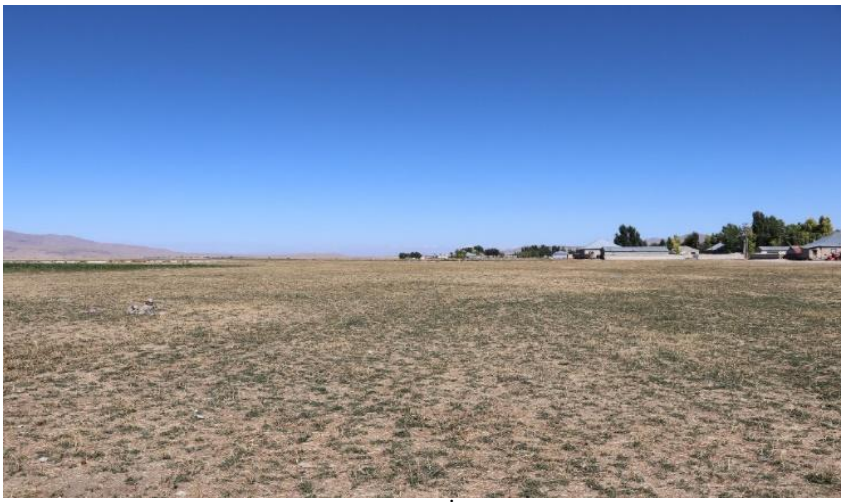

Fotoğraf 19. Molla İbrahim Höyük
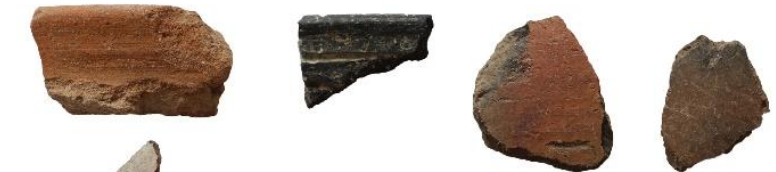

372
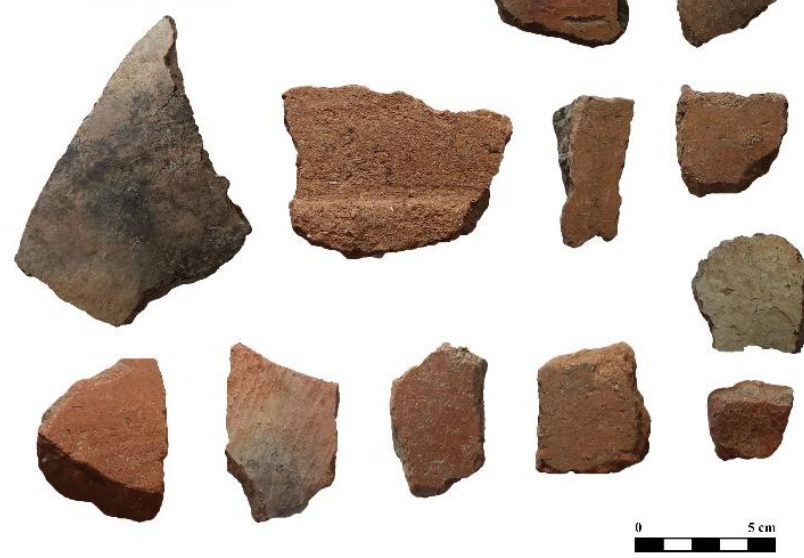

Fotoğraf 20. Molla İbrahim Höyük Keramik Fotoğrafları
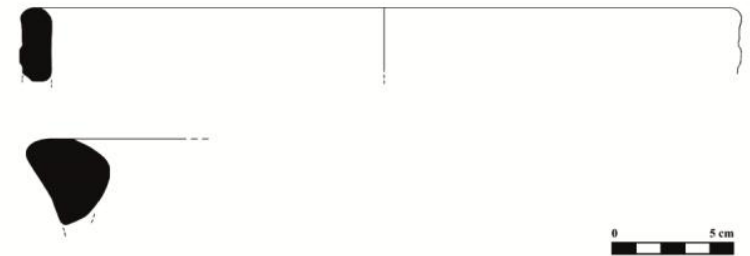

Cizim 4. Molla İbrahim Höyük Keramik Cizimleri 


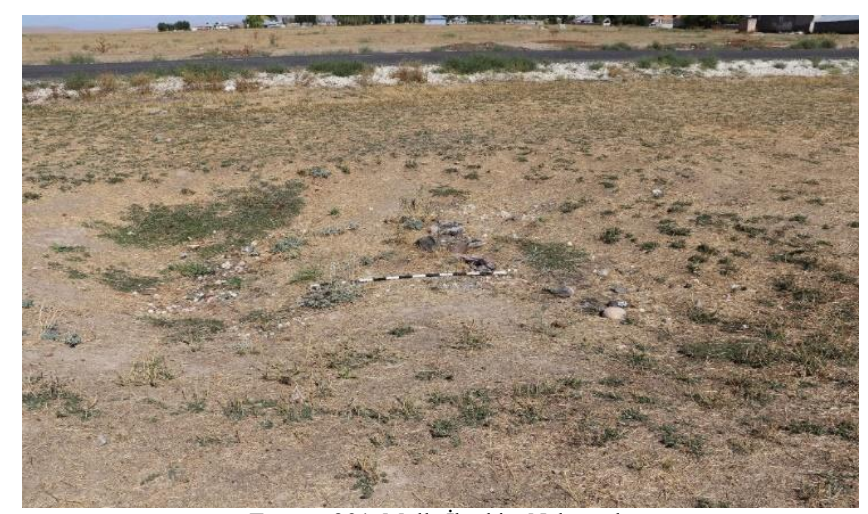

Fotoğraf 21. Molla İbrahim Nekropolü

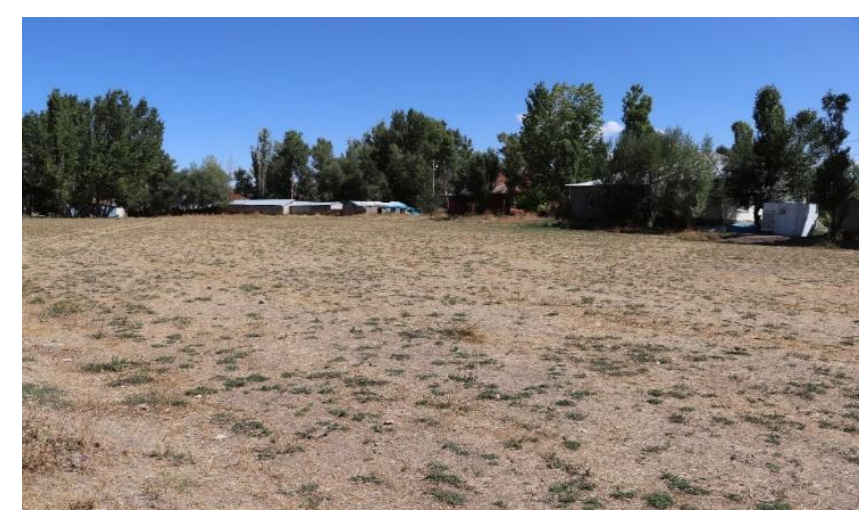

Fotoğraf 22. Çay Mahallesi Yerleşmesi

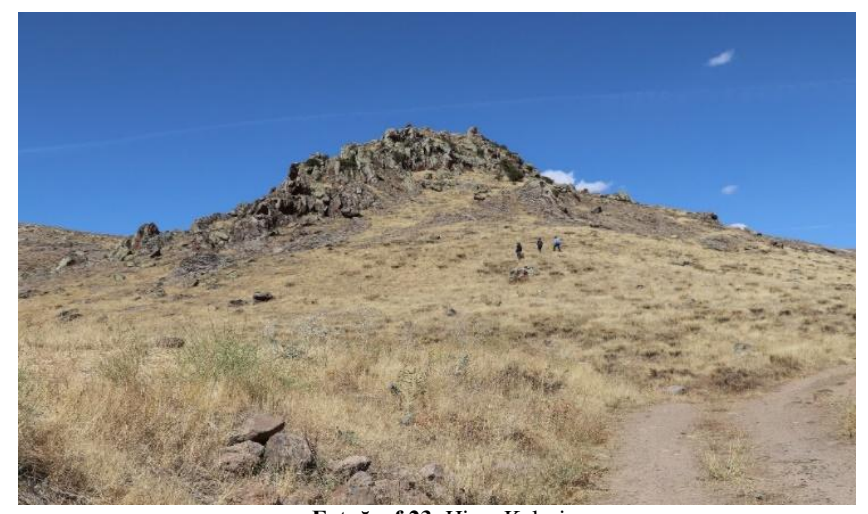

Fotoğraf 23. Hisar Kalesi 